\title{
Deus, a Bíblia e os evangélicos na Constituinte (1987-1988)*
}

\author{
God, the Bible and evangelicals in the Constituent \\ Assembly (1987-1988)
}

\section{Dios, la Biblia y los evangélicos en la Constituyente (1987-1988)}

Sydnei Melo**

\begin{abstract}
RESUMO
A Assembleia Constituinte de 1987-1988 contou com uma participação, nunca antes vista, de um grande contingente de deputados de confissão cristã evangélica (protestantes e pentecostais), que foram reconhecidos enquanto uma "grande novidade" política para a época. O propósito deste artigo é evidenciar seu protagonismo em dois dos debates em que se envolveram: a defesa da presença regimental de um exemplar da Bíblia na Mesa da Assembleia Constituinte, e do registro da expressão "sob a proteção de Deus" no preâmbulo da Constituição. Argumentamos que, nas duas discussões, os parlamentares evangélicos sustentam suas posições como que amparadas em uma fé cristã majoritária no país, ao mesmo tempo em que faz de seus posicionamentos um registro de demanda política dos próprios evangélicos, afirmando sua colocação em uma disputa maior no interior do campo religioso. Palavras-chave: Religião e política; Protestantismo e aspectos políticos; Brasil; Assembleia Constituinte (1987-1988).
\end{abstract}

\begin{abstract}
The Constituent Assembly of 1987-1988 had a never before seen participation of a large contingent of members of evangelical Christian confession (Protestants and Pentecostals), who were recognized as a political "great novelty" for the time. The purpose of this article is to highlight their prominence in two of the debates in which they were involved: the defense of the regimental presence of a copy of the Bible in the Table of the Constituent Assembly, and the registration of the expression "under the protection of God" in the preamble of the Constitution. We argue that in both discussions, evangelical parliamentarians hold their positions as being supported by a majority Christian faith in the country, while making their positions as a record of political demand of the evangelicals themselves, stating their placement in a larger dispute in the interior of the religious field.

Keywords: Religion and politics; Protestantism and political aspects; Brazil; Constituent Assembly (1987-1988).

\section{RESUMEN}

La Asamblea Constituyente de 1987-1988 contó con una participación, nunca antes vista, de un gran contingente de diputados de confesión cristiana evangélica (protestantes y pentecostales), que fueron reconocidos como una "gran novedad" política para la época. El

\footnotetext{
* Este artigo é fruto de pesquisa realizada com apoio da Coordenação de Aperfeiçoamento de Pessoal de Nivel Superior - Brasil (CAPES).

** Doutorando em Ciência Política (IFCH/Unicamp).
} 
propósito de este artículo es evidenciar su protagonismo en dos de los debates en que se involucraron: la defensa de la presencia regimental de un ejemplar de la Biblia en la Mesa de la Asamblea Constituyente, y del registro de la expresión "bajo la protección de Dios" en el preámbulo de la Constitución. Argumentamos que, en las dos discusiones, los parlamentarios evangélicos sostienen sus posiciones como que amparadas en una fe cristiana mayoritaria en el país, al mismo tiempo que hace de sus posicionamientos un registro de demanda política de los propios evangélicos, afirmando su colocación en una disputa mayor en el interior del campo religioso.

Palabras clave: Religión y política; Protestantismo y aspectos políticos; Brasil; Asamblea Constituyente (1987-1988).

"Tudo o que for louvado ali deve ser praticado, tudo o que for condenado ali deve ser proscrito". Esta citação encontra-se nas páginas de uma edição da revista $V_{e j a}$, publicada no ano de 1987, e é atribuída ao deputado goiano Antônio de Jesus (PMDB), que estaria a se referir à Bíblia Sagrada. O contexto desta afirmação: a Assembleia Nacional Constituinte (1987-1988) ${ }^{1}$, etapa relevante da história política recente do Brasil, e na qual despontaria a "grande novidade"2 que era a eleição de 33 deputados de confissão cristã evangélica - incluindo-se protestantes e pentecostais - para o parlamento brasileiro $^{3}$. A reportagem apontaria com esta frase a ilustração de uma meta que estaria no horizonte de atuação dos deputados evangélicos no parlamento nacional, qual seja: "a Carta Magna de uma nação deve basear-se na carta magna de Deus aos homens, que é a Bíblia”4 (cf. PIERUCCI, 1996, p. 164).

O registro da revista parece coerente com as ideias do deputado. Afirmação próxima desta consta nos Diários da Assembleia Nacional Constituinte ${ }^{5}$. Em 25 de junho de 1987, o parlamentar sobe a tribuna:

Sr. Presidente, Srs. Constituintes, certo estadista declarou: "A Bíblia é a carta magna dos pobres e oprimidos. A raça humana não está em condições de dispensá-la".

1 Doravante, "ANC".

2 O comentário é do então presidente, José Sarney: "toda Assembleia Constituinte tem uma grande novidade e a novidade dessa Constituinte é a presença maciça de uma representação evangélica". Jornal do Brasil, 7 de agosto de 1988, Caderno B, p. 6 (cf. FRESTON, 1993, p. 226).

3 Este número representava praticamente o dobro do número de deputados evangélicos - considerando protestantes históricos e pentecostais - até então eleitos para o parlamento nacional: desde a legislatura de 1946-1951, a presença de parlamentares de origem protestante em nível federal havia chegando ao máximo de 17 cadeiras (na legislatura de 1983-1987). Particularmente entre os pentecostais, este crescimento era ainda mais espantoso: entre 1946 e 1987, apenas 5 mandatos haviam sido exercidos por pentecostais; nas duas legislaturas anteriores à Constituinte, os assembleianos, mais especificamente, haviam contado com apenas um representante. Agora, entre os 33 constituintes evangélicos, 18 tinham origem pentecostal, sendo 14 vinculados à Assembleia de Deus (FRESTON, 1993, p. 167; 171; 192).

4 “Os deputados de Deus". Veja, $1^{\circ}$ de julho de 1987, p. 48.

5 Doravante, "DANC".

6 Apesar da menção a um "estadista”, a frase é a Thomas Huxley, biólogo britânico conhecido por sua ardorosa defesa da teoria da evolução das espécies - que o fez ser conhecido, inclusive, pelo sugestivo 
Eu acredito que, de fato, a Bíblia é a constituição espiritual do homem. E, apesar de haver sido concluída há cerca de dois milênios, nunca precisou ser remodelada. O homem muda, a sociedade se transforma, a Ciência evolui, mas a Bíblia continua sendo aplicável, nunca perde a sua modernidade e eficácia (DANC, 26/06/1987, p. 2921-2922).

Antônio de Jesus não era novato em política, já tendo exercido cargos públicos e representativos ${ }^{7}$. Ligado à Assembleia de Deus e eleito para a ANC com quase 50 mil votos, seu estilo de fazer política soava semelhante ao de qualquer frequentador de igreja evangélica: "o de pastor piedoso preocupado e algo chocado com o comportamento moral da comunidade" (FRESTON, 1993, p. 199; cf. RODRIGUES, 1987, p. 314). As primeiras iniciativas adotadas pelo parlamentar no início de seu mandato tendem a evidenciar esta identidade.

A respeito do Regimento Interno da ANC, Antônio de Jesus apresentou três emendas, que versavam, entre outras coisas, sobre a importância de se advertir e evitar o uso de "expressões descorteses e insultuosos" pelos membros da Assembleia ${ }^{8}$, e também sobre a necessidade de se impedir o uso de tabaco nos recintos do Congresso Nacional'. Destacamos, no entanto, a emenda de número 681, apresentada pelo deputado com a intenção de incluir artigo ao regimento interno que fizesse constar obrigatoriamente a presença de um exemplar da Bíblia Sagrada na Mesa da ANC. O constituinte justifica sua demanda:

A Bíblia Sagrada, conhecida como “o Livro dos livros”, por ser um dos grandes códigos da Humanidade, é inúmeras vezes consultado como fonte de referência por historiadores, sociólogos, antropólogos, além de religiosos de diferentes credos e origens. É respeitada pela sua atualidade e valorizada não só pelos cristãos, mas por todos os homens que vêem na Bíblia o livro-símbolo da impressão descoberta por Guttenberg.

apelido de "o buldogue de Darwin". Apesar disto, e também do fato ter ser um defensor do agnosticismo (sendo, inclusive, responsável pela criação deste termo), Huxley não se colocava em posição contrária àqueles que defendiam o ensino e leitura da bíblia nas escolas elementares britânicas - desde que isto se desse a partir de perspectivas que valorizassem seus aspectos gramaticais, geográficos e históricos, e não seus aspectos teológicos (cf. HUXLEY, 1883, p. 33-55).

Nascido em Anápolis, Antonio de Jesus já havia se candidatado a uma vaga na Assembleia Legislativa goiana em 1978, pela ARENA, obtendo a suplência. A extinção do bipartidarismo o levara ao PDS; posteriormente, se filiaria ao PMDB. O futuro constituinte ocupou cargos públicos por indicação política até o ano de 1980, quando assumiu mandato de deputado estadual, assim mantendo-se até 1982, quando concorreu novamente ao legislativo estadual, sem sucesso. Sua trajetória política se iniciara como líder sindical dos taxistas de Goiânia, e seu trabalho como evangelista, atuando junto a programas radiofônicos evangélicos, consolidou sua imagem como liderança religiosa.

8 Emenda $n^{\circ} 46$, de fevereiro de 1987.

9 Emenda $n^{\circ}$ 682, de fevereiro de 1987. 
Sendo o povo brasileiro fundamentalmente cristão, achamos oportuno sugerir que sempre haja um exemplar da Bíblia Sagrada à disposição dos Constituintes, pois assim estaremos em consonância com as crenças do nosso povo, e da moral cristã consubstanciada no Decálogo, destacando o respeito à vida e ao patrimônio alheios e ao amor ao próximo (BRASIL, 1987, p. 178)

A proposta, ao menos de acordo com os registros que constam nos DANC, não foi objeto de maiores polêmicas naquele 10 de março de 1987, dia em que ocorreu a votação que permitiu a aprovação da emenda que daria origem ao art. 46 do Regimento Interno da $\mathrm{ANC}^{10}$. O momento da votação conta com uma singela declaração de apoio do deputado Luiz Henrique (PMDB-SC), e com uma justificativa do senador Fernando Henrique Cardoso (PMDB-SP), relator do Regimento Interno, para a aceitação da emenda. Segundo o senador por São Paulo, a "questão da Bíblia" teria sido resolvida a partir de um acordo sem dificuldades com o deputado catarinense citado acima, esclarecendo também que teria sido alertado pelo parlamentar evangélico Manoel Moreira (PMDB-SP) a respeito da presença de um crucifixo no recinto: "embora o Estado seja laico", observou o senador, "como já temos um Crucifixo, me pareceu que seria muito justo tivéssemos também a Bíblia” (DANC, 11/03/1987, p. 708).

É certo que a aposição de crucifixos em espaços parlamentares e outros espaços públicos não deixou de ser, historicamente, objeto de polêmica e crítica. As primeiras manifestações contrárias de que se tem registro podem ser identificadas ainda no século XIX, nos anos finais do Império e nos primeiros anos da República brasileira. Partindo especialmente de protestantes, positivistas e republicanos, a crítica da presença da imagem do Cristo crucificado em parlamentos e tribunais de júri gerou repercussões e também reações notáveis por parte de representantes do catolicismo no país que, em alguma medida, seguiram a ver suas demandas prevalecendo - resultado visível de uma forte impregnação do catolicismo na mentalidade nacional e de suas relações de proximidade com instituições estatais e formalmente laicas (RANQUETAT JÚNIOR, 2012b, p. 87-99). Mais especificamente em relação ao parlamento nacional, importantes controvérsias sobre o tema foram protagonizadas a partir da década de 1940 pelos políticos do Partido de Representação Popular (PRP), de orientação conservadora, cristã e nacionalista, capitaneado por Plínio Salgado, uma das principais lideranças integralistas que tivemos no Brasil. Em 1947, Gofredo da Silva Telles Júnior, deputado federal pelo PRP, requereu a entronização do crucifixo no Palácio Tiradentes, antiga

10 Diz o texto do artigo: "A Bíblia Sagrada deverá ficar sobre a Mesa da Assembleia Nacional Constituinte, à disposição de quem dela quiser fazer uso" (DANC, 25/03/1987, p. 879). 
sede do Congresso Nacional - o que foi aceito, mas não sem resistência de deputados como o protestante Guaraci Silveira, o espírita Campos Vergal e também o católico Luiz de Toledo Piza Sobrinho, entre outros parlamentares socialistas, comunistas, liberais e positivistas. Com a transferência da Câmara Federal para Brasília, na década de 1960, a discussão voltaria à tona com os requerimentos do então deputado Plínio Salgado pela afixação do crucifixo na casa legislativa, que receberiam apoio da maioria do parlamento.

A presença de crucifixos no interior do espaço parlamentar e também de outros espaços institucionais e públicos brasileiros remete, portanto, a um debate de longa data, remontando ao período colonial e atravessando os anos, estendendo-se ao período republicano e aos nossos dias. Habitualmente encontrado em posições centrais e destacadas em espaços como escolas, universidades e tribunais, além dos parlamentos, a afixação de crucifixos nestes locais é tida por muitos como expressão de uma "cultura cristã brasileira" - neste caso, com um viés claramente relacionado a uma simbologia cristã de matriz católica, próprio da raiz lusa de nossa formação cultural. Expondo argumentos de juristas e especialistas em direito, Carlos Alberto Ranquetat Júnior (2012a, p. 61-69) nos mostra que os atualmente favoráveis à presença de crucifixos em espaços públicos baseiam-se em determinados olhares sobre este símbolo: o que enxerga o crucifixo como objeto que expressa o "espiritualismo do povo brasileiro" e como símbolo histórico; o que o vê como símbolo civilizacional de valor universal; o que o reconhece como símbolo ético e, finalmente, como símbolo cultural. Parece viger nestas observações uma compreensão diluidora do caráter afirmativamente religioso do crucifixo, ressaltando seu vínculo a uma tradição histórica presente no Brasil, ou a uma representação de valores universais e comuns (cf. GIUMBELLI, 2012, p. 51).

A sustentação da proposta de emenda defendida pelo deputado Antônio de Jesus, aparentemente, caminha no mesmo sentido. As preocupações ali registradas residem, em um primeiro momento, na demonstração da Bíblia Sagrada como um livro relevante para a humanidade como um todo, objeto de interesse de crentes e não crentes, de estudiosos dos diversos campos das ciências humanas, e mesmo como uma espécie de ícone da evolução dos meios de comunicação. Previamente, portanto, há um valor histórico e social que justifica a pertinência de haver um exemplar da Bíblia disponível para os constituintes. Mas há também um valor de ordem cultural e, especialmente, religiosa: diante do fato de o povo brasileiro ser "fundamentalmente cristão", a disposição de uma Bíblia para os parlamentares significa apresentá-la como um canal para que estes, com suas ações e suas palavras, estivessem em consonância com as crenças do povo deste país.

A presença da Bíblia Sagrada na Mesa da ANC é uma bandeira que, uma 
vez ratificada, será recorrentemente recordada pelo deputado. É do próprio a iniciativa de entrega do exemplar da Bíblia a ser exposto no recinto da Câmara dos Deputados, o que ocorre no dia 25 de março de 1987 (cf. DANC, 26/03/1987, p. 937-938). Em 28 de janeiro de 1988, Antonio de Jesus observa novamente a presença regimental da Bíblia no plenário, ressaltando a seriedade de sua presença e o sentimento de justiça que motivava: "é o maior código que a humanidade já conheceu, porque ela é quem traz o estatuto da criação do homem, da criação do universo. Tudo que o homem precisa saber em relação ao seu próximo consta desta Constituição" (DANC, 29/01/1988, p. 6665). Em 28 de abril de 1988, a Bíblia também justifica uma advertência do parlamentar a conflitos e ofensas protagonizadas por deputados no plenário da Câmara: “o caminho ideal é o acordo, é o entendimento. Nessa Bíblia que está aberta diante de nós, está escrito que o sábio Salomão já dizia há 3000 anos: 'afasta-te do caminho dos insensatos, e vivei. E procurai o caminho do entendimento e do respeito ao próximo" (DANC, 29/04/1988, p. 10010).

Não apenas Antônio de Jesus, mas também outros deputados, evangélicos em sua maioria, farão referências elogiosas à presença da Bíblia no interior do parlamento. Orlando Pacheco (PFL-SC), por exemplo, felicita seu colega pela proposta de emenda:

Admiro esta atitude e aceito-a como primeiro passo para o desenvolvimento do processo constitucional, visto que a Bíblia Sagrada é o livro que representa a primeira, maior e melhor Constituição que o mundo já recebeu. (...) A partir de sua efetivação todos os interessados poderão usufruir dos ensinamentos e das palavras de orientação bíblicas para a vida moral, social e cultural de cada um (DANC, 14/03/1987, p. 763).

João de Deus Antunes (PDT-RS), por sua vez, sobe à tribuna para manifestar sua alegria pela presença de um exemplar da Bíblia nas dependências da Assembleia Nacional Constituinte:

Queremos parabenizar os Srs. Constituintes que votaram favoravelmente, ensejando esta grande oportunidade que representa uma vitória para os cristãos brasileiros. (...) A Bíblia é um livro simples quando fechado, mas de grande valor quando aberto e estudado. Ele nos mostra o caminho para o céu e abre a porta da eternidade com Cristo. Oxalá esta Nação passa a ler mais a Bíblia Sagrada (DANC, 27/03/1987).

Matheus Iensen (PMDB-PR), meses depois, seria outro deputado a elogiar a iniciativa:

Com imenso júbilo, ocupo esta tribuna para exultar da oportunidade que doravante teremos de compartilhar neste recinto do maior ensinamento contido em qualquer livro que se tenha conhecimento. 
Sr. Presidente, Srs. Constituintes, estou me referindo à "Bíblia Sagrada", o livro dos livros, que hoje é parte integrante do nosso meio, através da Emenda no 681 - art. 46 - de autoria do ilustre Deputado Antônio de Jesus, ao Projeto de Resolução no 02/87, que dispõe sobre o regimento interno da Assembleia Nacional Constituinte (DANC, 27/08/1987, p. 4986).

Eliel Rodrigues (PMDB-PA), ao relatar as homenagens ao "Dia da Bíblia”, pronunciou:

Fato notável e digno de registro ocorreu neste Parlamento, em sua sessão do dia 23 de fevereiro deste ano, quando foi aprovado o Projeto de Resolução n ${ }^{\circ} 02$, de autoria do nobre Deputado Federal Antônio de Jesus, para que fosse colocada, na Mesa da Assembleia Nacional Constituinte, uma Bíblia, à disposição do que dela queiram fazer uso (DANC, 16/12/1987, p. 6138).

Os discursos acima concentram os argumentos que enobrecem a emenda aprovada pelo parlamento, mas são uma parte deles. A menção à presença da Bíblia no recinto parlamentar em pronunciamentos com propósitos os mais variados: é tomada como fonte de referência para a compreensão da "permissividade" social e sua relação com o alastramento da AIDS $^{11}$,para a abertura do debate sobre a pena de morte ${ }^{12}$, para a defesa da reforma agrária ${ }^{13}$, a defesa da família ${ }^{14}$, a advertência sobre as injustiças

11 Fala do deputado Orlando Pacheco (PFL-SC): “o pânico gerado por esta peste, que pode ser consagrada como símbolo da permissividade que toma conta de todos os setores da sociedade brasileira, mobiliza especialistas, governantes, religiosos e políticos na denúncia do mal, mas pouco se conscientizam de que o homem apenas colhe os frutos de sua desobediência de Deus. Este exemplar da Bíblia Sagrada, aqui disponível conforme dispositivo do Regimento, diz-nos sobre o assunto em questão" (DANC, 11/04/1987, p. 1279).

12 Francisco Rossi (PTB-SP): "nós, Constituintes, aprovamos investidos no poder que nos foi delegado pelo povo, aprovamos o Regimento Interno que autoriza colocar sobre esta mesa a palavra de Deus, a Bíblia Sagrada, e eu lembro aqui a passagem bíblica que faz referência às Potestades, que todo poder temporal emana do Poder Divino. E lembro que esta mesma Bíblia que está aí em cima, no Velho Testamento, faz diversas referências à pena de morte. (...) Em se tratando de um Livro que está aí sobre nossa mesa, o qual aprovamos que fosse ali colocado, por que não invocá-lo também, assim como a palavra de Deus, para que pudéssemos pelo menos discutir esse assunto, discutir esse tema sem paixão e sem qualquer outra intenção a não ser a de resguardar a integridade física da família brasileira" (DANC, 23/04/1987, p. 1459).

13 Nelson Aguiar (PMDB-ES): "por mais que queiram e aqui existem aqueles acostumados a pichar xiitas, pichar esquerdistas, pichar drusos e outras coisas, não estou fazendo nenhum discurso inspirado em O Capital, de Karl Marx. Ainda não, ainda não! Estou fazendo o meu discurso inspirado no livro, que está sobre a mesa, porque, desde a minha infância, sou criado aos pés do Evangelho. O que me inspira é a passagem dos Profetas advertindo a todos nós que o direito tem que trazer em si o conteúdo da justiça, que é um atributo de Deus na relação dos homens” (DANC, 17/07/1987, p. 3359).

14 Aparte do deputado Antônio de Jesus ao discurso do deputado Costa Ferrreira (PFL-MA): “agradeço ao nobre colega e quero também, neste instante, compactuar com V. Ex ${ }^{a}$ por ter tratado de assunto de suma relevância, neste momento, quando está de posse, inclusive, da Bíblia Sagrada, que é o código mais antigo da Humanidade, que traz referências sobre a primeira instituição familiar do universo" (DANC, 3/08/1987, p. 3836). 
sociais $^{15}$, etc. Mas talvez um dos casos mais curiosos de referência à presença da Bíblia tenha sido protagonizado pelo deputado Victor Faccioni (PDS-RS), que sequer era ligado à "bancada evangélica". No dia em que o constituinte Antônio de Jesus entrega o exemplar da Bíblia a ser utilizado no recinto da Assembleia, o parlamentar gaúcho, às vésperas do encerramento da sessão daquele dia, sobe a tribuna para dizer o seguinte:

por curiosidade, fui ver em que parte estava aberta a Bíblia. Disse-me o Sr. Presidente que a havia aberto aleatoriamente. Seria oportuno fazer um breve exame do que se encontra à página 82 da Bíblia, aberta sobre a mesa da Assembleia Nacional Constituinte, pois parece que, como tudo de que trata este livro santo, há alguma coisa a ver com o momento presente da história da nação brasileira.

E assim procedeu o deputado gaúcho, com a leitura do capítulo 18 do Livro de Êxodo, versículos 13 a 27, sessão intitulada "A nomeação de auxiliares", que relata os questionamentos de Jetro a seu genro, Moisés personagem que no relato do Velho Testamento é responsável pela condução dos hebreus à fuga do Egito. No trecho em questão, Jetro se mostra incomodado com o fato de Moisés assumir solitariamente a tarefa de julgar os questionamentos de seu povo, lhe sugerindo que levante homens capazes e tementes a Deus para que lhe auxiliem e julguem as causas menores e mais simples, reduzindo o fardo de seu líder. Ao final do texto, Moisés, atende à sugestão de seu sogro, selecionando seus auxiliares.

Ao concluir a leitura, Faccioni completa seu discurso:

Que esses ensinamentos sirvam para todos nós, sirvam inclusive a S. Exa o Presidente da República, que tem a grave responsabilidade de conduzir os destinos desta Nação, escolhendo, dentro os melhores, os seus ministros, que devem propor e executar a política governamental, nesta hora em que essa política carece de definições, mormente na área econômico-financeira e, por consequência, na área social ${ }^{16}$.

15 Salatiel Carvalho (PFL-PE): "neste ponto queremos usar uma expressão da Bíblia Sagrada, livro dos livros que honra a tribuna desta Assembleia, onde está sabiamente colocada. Diz a expressão bíblia que 'quem semeia vento, colhe tempestade...'. Que outro resultado poderia se esperar? Que outro tipo de reação a não ser a demonstração da insatisfação e da revolta da maioria oprimida? Se temos plantado e cultivado a injustiça social, que outros frutos poderíamos colher?" (DANC, 9/08/1987, p. 4137).

16 Em 25 de junho de 1987, o deputado Antônio de Jesus relembraria as declarações do deputado Victor Faccioni: "naquela ocasião estavam sendo escolhidos os Presidentes e Relatores das Comissões e Subcomissões. Coincidência ou não isto vem demonstrar que a Bíblia tem sempre algo a nos dizer. Independentemente do local ou das circunstâncias, ela marca sua presença de forma significativa" (DANC, 26/06/1987, p. 2922). 
Concluindo o episódio, o presidente em exercício naquela sessão, o deputado paulista Arnaldo Faria de Sá (PTB), complementa a explanação anterior: "o nobre Constituinte leu a página da Bíblia que estava aberta. Entretanto, na página seguinte, estão inscritos os dez mandamentos. Que a nossa Constituinte seja como os dez mandamentos para o povo brasileiro" (DANC, 26/03/1987, p. 946-947).

Encerrava-se a sessão.

\section{A "primeira grande vitória"}

O caráter unânime da votação que assegurou a presença da Bíblia no interior da Assembleia Nacional Constituinte ${ }^{17}$ poderia transmitir a impressão de um amplo consenso sobre o tema. Contudo, os próprios deputados evangélicos manifestariam, em outros momentos, que tal demanda enfrentara contestações. É da parte de Antônio de Jesus que ouvimos, por exemplo, o seguinte pronunciamento:

Quando apresentei a emenda para colocação da Bíblia sobre a mesa da Assembléia Nacional Constituinte muitos tentaram dissuadir-me de tal propósito. Alguns alegavam que não se devia misturar religião com política. Outros diziam que tal ato poderia ser interpretado como folclórico.

Eu não dei ouvidos a nada disso, porque sabia que, no mínimo, a presença da Bíblia nos levaria a refletir sobre nossa condição de Constituintes, até porque não se deve confundir Bíblia com religião, posto que ela é a revelação de Deus aos homens (DANC, 26/06/1987, p. 2922).

Não é possível dizer exatamente quantos deputados eram contrários à proposta de Antônio de Jesus, mas é possível deduzir a existência de críticas a ela. Entre os deputados de partidos de orientação à esquerda, esta posição é bastante provável. A manifestação mais contundente que identificamos, neste caso, vem do constituinte Haroldo Lima (PCdoB-BA), pronunciado em 23 de julho de 1987 em reunião ordinária da Comissão de Sistematização. Ao justificar sua posição contrária à Proposta de Emenda Popular n ${ }^{\circ} 4$, que exigia do Estado brasileiro a garantia do ensino religioso para a educação básica, o deputado aponta a obrigatoriedade do exemplar da Bíblia Sagrada nas sessões como resultado de "intransigência e sectarismo religioso" no interior da ANC. Diz, dirigindo-se ao presidente em exercício da Comissão:

17 O presidente da Assembleia, o deputado Ulysses Guimarães (PMDB-SP), procedeu à votação simples da emenda, convocando os favoráveis a ela a permanecer como estivessem, sem ocorrência de manifestação contrária (DANC, 11/03/1987, p. 708). 
"na mesa em que V. Ex ${ }^{a}$ preside a reunião existe uma Bíblia aberta. Isto foi inserido aqui na calada da noite, quando a Constituinte não pôde deliberar a respeito do assunto com maior amplitude". Para o parlamentar comunista, tal decisão era uma violação da liberdade de consciência: "eu como diversos outros membros desta Constituinte não concordamos com aqueles que pediram que se colocasse a Bíblia aí, como não deveria estar aí também $\mathrm{O}$ Capital nem deveria estar aí o livro de Maomé”, defendendo, finalmente, que "a questão do Estado, a questão da organização Constituinte deve ser arreligiosa, deve ser aconfessional" (DANC, sup. no 132, 22/08/1987, p. 476).

Mesmo sem manifestar-se formalmente contrário à questão, o senador Fernando Henrique Cardoso também parecia adotar tal posição. A justificativa para acolher a Proposta de Emenda $n^{\circ}$ 681, em decorrência do "alerta" sobre a presença do crucifixo no parlamento, pouco espaço nos abre para compreender o que de fato o senador paulista defendia sobre o assunto. "Embora o Estado seja laico", parecia que o parlamentar buscava expressar um gesto de boa vontade para com uma demanda dos representantes evangélicos. Mas sua fala era genérica, vacilante, sem preocupação em enveredar discussões mais detalhadas sobre o tema. Além disso, a continuidade do comentário do senador merece nota: ele pronuncia suas impressões sobre outra proposta de emenda ao Regimento Interno feita pelo deputado Antônio de Jesus, a de $n^{\circ}$ 682, que versa sobre a proibição do fumo nas dependências do Plenário. Apesar de se dizer partidário às preocupações do parlamentar goiano, pronuncia: "não fumo e tenho horror ao fumo, mas em nome da convivência democrática, como já temos tolerado tantas coisas, vamos pedir aos nossos Companheiros que fumem um pouco menos, e continuem fumando" (DANC, 11/03/1987, p. 708, grifos nossos). Sobre o episódio, vale a consideração das notas de Douglas Pinheiro (2008, p. 22): o pesquisador enxerga, especialmente na expressão "como já temos tolerado tantas coisas", um lapso de discurso, uma pulsão censurada. O termo "tolerância", tendo conteúdo histórico de grande relevância, não seria pronunciado de forma desconhecida por um intelectual de vasta publicação. Na interpretação de Pinheiro, a presença da Bíblia na Mesa do Plenário Constituinte - na visão do senador e Relator do Regimento Interno - não decorreria do reconhecimento de direito e de igual respeito e consideração quanto ao uso dos símbolos religiosos naquele espaço, mas "de uma liberalidade da maioria que atendeu a uma reivindicação não-ameaçadora da minoria".

Por outro lado, em 15 de julho de 1987, o deputado Salatiel Carvalho (PFL-PE) pronunciaria palavras um pouco mais carregadas: 
A primeira grande vitória que conseguimos foi obtida ainda na fase preliminar de elaboração do Regimento Interno, quando o Plenário aprovou por unanimidade a Emenda de autoria do Deputado Antônio de Jesus - PMDB-GO, da Assembleia de Deus, tornando legal a colocação da Bíblia Sagrada sobre a mesa principal, nas sessões da Constituinte. A emenda foi aprovada apesar de ter sido rejeitada pelo Relator, Fernando Henrique Cardoso, um ateu que se recusou até mesmo a comentar a emenda quando pedimos que ela fosse votada em destaque. A recompensa do Senador ateu veio logo na fase seguinte, quando ele disputou o principal cargo da Constituinte, o de Relator-Geral da Comissão de Sistematização. Figurando em todas as pesquisas da imprensa como Relator da Constituinte e vencedor da disputa, foi derrotado com margem de votos aproximada do nosso grupo que pertence ao PMDB e que não lhe deu apoio (DANC, 16/07/1987, p. 3313, grifos nossos).

Fernando Henrique Cardoso era o líder do PMDB no Senado e ambicionava o cargo de Relator-Geral da Comissão de Sistematização, responsável pela elaboração do projeto de texto constitucional. Segundo notícias publicadas à época, Cardoso era, junto com o deputado mineiro Pimenta da Veiga, os nomes que mais interessavam ao grupo político liderado por Ulysses Guimarães (PMDB-SP), presidente da ANC, para a ocupação do cargo de Relator-Geral. No entanto, Guimarães já vinha enfrentando resistências e derrotas políticas em razão da atuação estratégica de um setor de centro-esquerda do partido, liderado pelo senador paulista Mário Covas - naquele momento, o político mais votado da história do país, com mais de 7 milhões de votos obtidos para o Senado em 1986 (PILATTI, 2008, p. 53). Exercendo uma "tríplice" presidência - do PMDB, da Câmara dos Deputados e da Assembleia Nacional Constituinte ${ }^{18}$ - Guimarães não foi capaz, contudo, de resistir ao avanço do setor liderado por Covas nos demais cargos em disputa. A crise interna do partido, e os questionamentos à enorme concentração de poderes na figura do "tripresidente" Guimarães, desembocariam em duas importantes derrotas para ele: a primeira diz respeito à liderança do partido na Constituinte, arrebanhada pelo próprio Mário Covas ${ }^{19}$, o que fortalecia a contestação interna ao comando do partido(cf. ROCHA, 2013, p. 76).

A segunda derrota se dá na escolha do Relator-Geral. A bancada peemedebista, sendo a maior da Constituinte, obteve a prerrogativa de escolha do ocupante do cargo. Fernando Henrique Cardoso e Pimenta da Veiga

18 Na disputa para a presidência da Câmara, Ulysses Guimarães venceu a candidatura de Fernando Lyra (PMDB-PE) por 299 votos, contra 155. A disputa para a presidência da Assembleia Nacional Constituinte foi mais tranquila: nova vitória de Guimarães contra Lysâneas Maciel (PDT-RJ) por 425 votos contra 69 (cf. PILATTI, 2008, p. 28).

19 A votação ocorreu em 18 de março de 1987. Covas derrotou Luiz Henrique (PMDB-SC) por 143 votos a 107 (cf. PILATTI, 2008, p. 53) 
apresentaram-se à disputa interna, que também contou com a participação do deputado amazonense Bernardo Cabral, apoiado por Mário Covas ${ }^{20}$. Apesar da posição politicamente relevante que já ocupava, Cardoso foi derrotado na votação em primeiro turno, obtendo 81 votos, enquanto Pimenta da Veiga e Bernardo Cabral passariam pela etapa com 86 votos cada. Na segunda rodada de votos, Fernando Henrique Cardoso declarou apoio a Pimenta da Veiga o que não contribuiu, no entanto, para a vitória do representante mineiro: Bernardo Cabral sagrou-se vencedor com 111 votos contra 90.

O setor peemedebista da "bancada evangélica" era composto de 15 deputados. Como a eleição do Relator-Geral se deu por voto secreto, não é possível saber, a princípio, a quem os deputados evangélicos do partido destinaram seus votos. O fato é que a derrota de Fernando Henrique Cardoso era recordada pelo deputado Salatiel Carvalho, em seu discurso acima mencionado, como uma espécie de consequência política - poderíamos dizer também, "espiritual"? - da rejeição do senador "ateu" à demanda dos parlamentares evangélicos pela presença da Bíblia Sagrada no recinto da ANC, uma "recompensa". Se realista, podemos concluir com a fala do deputado que a rejeição do senador paulista à emenda $\mathrm{n}^{\circ} 681$ teria incentivado os deputados evangélicos do partido a se oporem à sua candidatura à Relatoria-Geral da Comissão de Sistematização - uma situação que poderíamos considerar relevante no sentido de reconhecer o peso que os deputados evangélicos poderiam exercer na disputa de cargos e temas considerados cruciais no interior da ANC, considerando-se a pequena margem de votos que impediu a ida de Cardoso à segunda rodada daquela disputa.

Diante de tal cenário, portanto, é preciso refletir sobre o forte significado político representado pela presença da Bíblia na Mesa da Constituinte para os parlamentares da "bancada evangélica". O fato de isto ser compreendido como a "primeira grande vitória" do bloco não é trivial. Para Antônio de Jesus, como temos registrado, é questão de relevante importância. Outro episódio nos relembra isto. Em julho de 1988, o deputado goiano, cumprindo determinação regimental, assume brevemente a cadeira da presidência da ANC no lugar do constituinte Sotero Cunha (PDC-RJ), também evangélico, também assembleiano. Antes de permitir a continuidade dos trabalhos, dando a palavra ao deputado Adylson Motta (PDS-RS), Antônio de Jesus intervêm:

antes, porém, permita-me congratular-me com o nobre Relator Bernardo Cabral, por providenciar um exemplar da Bíblia Sagrada, que se encontra sobre a mesa da Presidência

20 Covas teve Cabral como seu vice-líder no MDB em 1969, quando ambos tiveram seus mandatos cassados em decorrência da implementação do Ato Institucional nº5 (ROCHA, 2013, p. 76). 
da Assembleia Nacional Constituinte (...). Quero também congratular-me com S. Ex pela capacidade e a dinâmica com que, em espírito solidário, tem levado a cabo os trabalhos da Relatoria da Assembleia Nacional Constituinte (DANC, 08/07/1988, p. 11914).

Em seguida, ainda durante o discurso do deputado gaúcho, Antônio de Jesus já teria se retirado para o retorno do deputado Sotero Cunha à presidência daquela sessão. Concordando com Pinheiro (2008, p. 38-40), é sugestivo das prioridades do deputado que sua preocupação mais premente ao assumir tão brevemente a presidência daquela sessão tenha sido a de assegurar a presença da Bíblia no recinto - possivelmente algo mais relevante do que o reconhecimento dos trabalhos do Relator-Geral, a quem se refere no final de seu pronunciamento, e que parece ter sido agraciado apenas em razão da recordação de ter sido responsável por providenciar o exemplar da Bíblia para aquele momento ${ }^{21}$.

Os eventos nos remetem a uma reflexão sobre a existência de uma luta simbólica por afirmação dos evangélicos no campo religioso (PINHEIRO, 2008, p. 37), que tem como mote a existência do exemplar bíblico nas dependências da ANC: do momento em que a Bíblia passa a ser exibida na Mesa do Plenário, a reivindicação por sua presença dá lugar à vigilância por sua permanência; e a recorrência discursiva dos deputados tanto à sua presença quanto à citação de trechos da Bíblia para justificação de suas posições políticas ressalta o seu papel como um ícone capaz de reduzir o valor de outros símbolos exibidos no recinto do Congresso, como o crucifixo. De fato, não constam dos registros da ANC reclamações de deputados evangélicos acerca da presença de crucifixos nos espaços institucionais em que atuavam, enquanto que a reivindicação pela presença da Bíblia se coloca notoriamente como uma reivindicação dos evangélicos. Além disso, se a motivação para a reivindicação da presença da Bíblia no parlamento baseava-se em uma suposta universalidade simbólica da mesma, de interesse não apenas para cristãos mas também homens de ciências e religiosos de diferentes credos, por sua vez a recorrência discursiva à Bíblia evidencia os esforços levados a cabo especialmente pelos deputados evangélicos para o fomento de uma legislação constitucional que tome seu livro sagrado, não como uma simples referência histórica, mas como a base de sua sustentação - como assinala o deputado Matheus Iensen:

21 Como observa Pinheiro (2008, p. 39-41), a exibição da Bíblia no parlamento poderia ser bastante compreensível para os evangélicos, mas não para os demais. É sugestivo que, no sumário do Diário da Assembleia Nacional Constituinte daquele dia, a referência à breve fala de Antônio de Jesus tenha sido resumida assim: "Congratulações da Mesa com o Constituinte Bernardo Cabral pelo desempenho na Relatoria da Assembleia Nacional Constituinte” (cf. DANC, 08/07/1988, p. 11886). 
todas as nações que tomaram por base a "Bíblia Sagrada" tornaram-se grandes e poderosas, e muito maior seremos se continuarmos lendo e aceitando seus grandes ensinamentos.

Para que a nossa Nação seja poderosa, façamos com que ela esteja alicerçada sobre a rocha inabalável - a "Bíblia Sagrada".

(...) Sr. Presidente, Srs. Constituintes, concluindo este pronunciamento, cito-lhes o maravilhoso salmo 33, versículo 12, que diz: "Bem-aventurada é a Nação cujo Deus é o Senhor".

Em outras palavras, diríamos que "feliz é a nação, grande é a Nação, bem-sucedida é a nação que tem por base a palavra de Deus, a Bíblia Sagrada" (DANC, 27/08/1987, p. 4986).

"Feliz" ou "Bem-aventurada" é a nação cujo Deus é o Senhor. Por diferentes traduções e estilos, o décimo segundo versículo do capítulo 33 do livro dos Salmos é um texto também recorrente na retórica dos constituintes evangélicos. Sua enunciação demonstra uma posição categórica: se a Bíblia deve ser o fundamento da nação, a submissão à vontade divina, como uma ordenação bíblica, deve ser a diretriz do Estado brasileiro.

Assim enuncia o deputado Gidel Dantas:

Vamos buscar na Bíblia Sagrada os princípios que devem transparecer na nova Constituição brasileira, especialmente aqueles que nos advertem para tomadas de posição coerentes com os compromissos assumidos durante a última campanha eleitoral. Destacamos a advertência que encontramos no livro de Isaías: "Ai dos que decretam leis injustas, dos que escrevem leis injustas, dos que escrevem leis de opressão, para negarem justiça aos pobres, para arrebatarem o direito dos aflitos do meu povo, a fim de despojarem as viúvas e roubarem os órfãos”. (Isaías, Cap. 10: vs. 1 e 2).

Pois feliz é a nação cujo Deus é o Senhor (DANC, 10/02/1987, p. 176).

\section{De semelhante modo, Costa Ferreira (PFL-MA):}

"Bem-aventurada é a nação cujo Deus é o Senhor", diz o Salmo maravilhoso tantas vezes invocado. Feliz é a Nação cujos homens pautam a sua conduta pelas palavras divinas e procuram seguir os exemplos que emanam da Bíblia Sagrada. (...) E que o Evangelho de Cristo seja o nosso guia e companheiro nesta jornada tão importante para os destinos do Brasil, senda de luz a iluminar o nosso caminho, para que o trabalho seja fecundo e dê bons frutos, perpetuando-se no tempo como uma obra de irmãos, feita com carinho e sem outro objetivo que não seja o bem dos nossos patrícios de todos os quadrantes desta Pátria, que nasceu sob o signo da cruz e há de crescer cada vez 
mais segundo os preceitos da Bíblia Sagrada, ela que contêm toda a sabedoria vinda de Deus em benefício de todos os homens (DANC, 16/12/1987, p. 6186).

Antônio de Jesus, artífice principal do debate em torno da presença da Bíblia no parlamento, não apenas defende a importância de as atenções da Nação estarem voltadas às expressões da vontade divina, com o mesmo apego à conclusão do salmista, como também a própria democracia - a verdadeira democracia - só pode ser compreendida enquanto amparada pela presença e proteção de Deus: "sem a presença de Deus, nada podemos fazer de bom para o povo, porque a presença de Deus, a proteção de Deus, é proteção através do amor, da justiça e da verdadeira democracia, que antes de democracia, é uma teocracia divina" (DANC, 29/01/1988, p. 6665, grifos nossos).

\section{Sob a proteção de Deus}

A última citação a que nos remetemos é a conclusão de um discurso em favor de outro tema objeto de polêmica nos debates da ANC: a presença de "Deus" no preâmbulo da Constituição Federal. No pronunciamento em questão, datado de 28 de janeiro de 1988, o deputado Antônio de Jesus não apenas defende sua concordância com a pauta, como também se vale do fato da presença regimental da Bíblia na Mesa da ANC como um argumento que orienta sua defesa: é a Bíblia que diz que é bem-aventurada a nação que tem a Deus como seu Senhor; é nela que constam os Dez Mandamentos, a Lei de Deus que esclarece o que é de fato necessários aos homens; é ela, finalmente, que registra as palavras do Cristo: "sem mim, nada podeis fazer". Concluindo: "que haja a presença de Deus no Preâmbulo da Constituição, porque sem a presença de Deus nada podemos fazer de bom para o povo".

A menção a Deus no preâmbulo das constituições brasileiras é recorrente: com exceção das Constituições de 1891 e 1937, as demais Cartas invocam a Deus em seus preâmbulos ${ }^{22}$. E tão frequente quanto este fato são os debates realizados em torno dele. No caso da Assembleia Constituinte de 1933-1934, que reintroduziu a invocação a Deus na Carta de 1934, resistências foram registradas por deputados contra esta e outras emendas que consideravam "religiosas" e voltadas a uma intenção de reconquista de privilégios perdidos pela Igreja Católica. A mais marcante delas foi protagonizada por Tomaz de Oliveira Lobo, que classificava a matéria como absurda e antiliberal, uma manifestação forçada de uma crença religiosa que

22 No caso da Constituição de 1824, período de vigência de um regime de união entre o Estado e a religião católica, a Constituição foi promulgada em nome da "Santíssima Trindade". O juramento da Constituição pelo Imperador D. Pedro I ocorreu em cerimônia realizada na catedral do Rio de Janeiro (RANQUETAT JÚNIOR, 2012b, p. 219) 
contrariava o princípio da liberdade de crença. Autor de emenda que buscou suprimir o preâmbulo em questão, o constituinte pernambucano também foi acompanhado em sua posição por outros deputados, como Zoroastro Gouveia, Edgard Sanches e Homero Pires. Por sua vez, na Constituinte de 1946, a iniciativa de suprimir a menção a Deus no preâmbulo constitucional partiu do deputado comunista Caires de Brito, sendo sua crítica acompanhada por outros deputados - como o já mencionado Guaraci Silveira, de origem protestante, e o deputado Café Filho, declaradamente agnóstico e um dos críticos mais contundentes da proposta.

Tal qual a demanda pela aposição de crucifixos, a invocação a Deus nos preâmbulos constitucionais também foi uma reivindicação apresentada por atores identificados com a religiosidade católica. No caso da Constituinte de 1946, inclusive, as duas medidas foram solicitadas pelo mesmo parlamentar, o deputado Gofredo da Silva Telles Júnior, evidenciando a dedicação dos integralistas ao registro da identidade da nação brasileira com o catolicismo ${ }^{23}$. Se outros deputados não tinham iniciativa semelhante, no entanto é comum encontrar em seus posicionamentos diferentes razões para a aceitação da proposta, pautadas desde uma noção de tolerância e compreensão da raízes culturais e sociológicas da formação cristã do povo brasileiro, como defendido pelo então deputado Gilberto Freyre; até a pura e simples indiferença se assegurado, contudo, o direito a não ter crenças - argumento do deputado socialista Hermes Lima (RANQUETAT JÚNIOR, 2012b, p. 219-225). O que estas situações evidenciam, de todo modo, é uma permanente presença do discurso de identificação entre os campos da política e da religião, por mais que assistamos historicamente a uma gradual modernização dos dispositivos constitucionais de garantia dos direitos civis relacionados à liberdade de consciência e de crença. A supressão da liberdade religiosa, que seria a marca de um Estado confessional, é substituída pela conciliação entre a liberdade de crença e a manutenção de uma identidade política e jurídica do Estado brasileiro com aspectos de uma religiosidade social e culturalmente dominante, e institucionalmente forte e influente - como é o catolicismo durante o século XX.

A invocação a Deus também se apresenta na Constituição de 1967. Não há o que se falar, contudo, sobre debates a respeito do tema, que neste caso

23 No caso da Constituinte de 1933-1934, a proposta de menção a Deus no preâmbulo constitucional foi da autoria do deputado Mário de Andrade Ramos. Apesar de compreender como adequada a separação entre o poder "espiritual” e o "temporal", Ramos defendia que a medida traria satisfação à população brasileira, de alma cristã, trabalhadora, bondosa e pacífica (cf. RANQUETAT JÚNIOR, 2012b, p. 220) 
simplesmente inexistiram ${ }^{24}$. Estas ressurgem durante as atividades da Constituinte de 1987-1988. E é conhecido que o preâmbulo de nossa mais recente Constituição registra sua promulgação "sob a proteção de Deus" 25. A expressão consta não apenas no preâmbulo, mas também no ritual ordinário das atividades parlamentares, uma vez que o presidente da Casa, ao iniciar a sessão do dia, tinha - e tem até os dias atuais - o dever de pronunciar: "sob a proteção de Deus e em nome do povo brasileiro, iniciamos nossos trabalhos"26.

O tema da presença de Deus no preâmbulo da Constituição foi objeto de discussão nas reuniões organizadas pela Comissão de Sistematização. $\mathrm{Na}$ data de 2 de setembro de 1987, por exemplo, a comissão ouviu aos comentários de Dom Raymundo Damasceno de Assis, que ali se encontrava para defender uma proposta de emenda dedicada ao tema da liberdade religiosa, patrocinada por entidades católicas. Entre outras coisas, a emenda solicitava a inclusão do nome de Deus no preâmbulo constitucional, defendida pelo bispo a partir da menção ao significado da religiosidade cristã na história do país e pelo fato de considerar a religião um elemento fundamental da cultura do povo brasileiro. A invocação ao nome de Deus nos preâmbulos das constituições anteriores à que estava em discussão eram, para o religioso, um reflexo da realidade da fé dos brasileiros, e tampouco seria esta uma extravagância brasileira, visto o uso de semelhante invocação em diversas Constituições espalhadas por países da América e da Europa. Partindo da compreensão de um Deus que interfere na história para a promoção dos direitos fundamentais

24 Imposta ditatorialmente, sob a condição de um Congresso Nacional esvaziado por cassações de parlamentares opositores, e com a obrigação apenas de promulgá-la, a Constituição de 1967 apresenta um preâmbulo sucinto: "o Congresso Nacional, invocando a proteção de Deus, decreta e promulga a seguinte Constituição do Brasil". Sobre ele, reproduzimos o comentário do professor Dalmo Dallari (2001, p. 264, grifos do autor): “esse é um falso Preâmbulo de uma falsa Constituição. A referência expressa ao Congresso Nacional é uma confissão da ilegitimidade, a invocação à proteção de Deus é simples fórmula retórica, pois naquele momento nem o povo nem a Igreja católica tinham condições para influenciar uma decisão política do comando militar, verdadeiro autor do novo texto apresentado na Constituição. E a referência sintética à 'Constituição do Brasil' deixou evidente que não se pretendia respeitar os preceitos do federalismo, pois todos os governantes, órgãos e administradores públicos estavam subordinados às determinações arbitrárias do comando militar superior".

25 Diz o preâmbulo: "Nós, representantes do povo brasileiro, reunidos em Assembléia Nacional Constituinte para instituir um Estado Democrático, destinado a assegurar o exercício dos direitos sociais e individuais, a liberdade, a segurança, o bem-estar, o desenvolvimento, a igualdade e a justiça como valores supremos de uma sociedade fraterna, pluralista e sem preconceitos, fundada na harmonia social e comprometida, na ordem interna e internacional, com a solução pacífica das controvérsias, promulgamos, sob a proteção de Deus, a seguinte Constituição da República Federativa do Brasil” (BRASIL, 2018, p. 9).

26 A determinação constou na Resolução nº1, de 1987, que estabelecia as normas para o funcionamento da Assembleia Nacional Constituinte até a aprovação de seu regimento interno. Quando este passou a vigorar, conforme a Resolução $n^{\circ} 2$ do mesmo ano, a obrigação foi mantida. 
da pessoa humana e de sua dignidade, Dom Raymundo Damasceno de Assis se felicitava em seu discurso ao reconhecer que a possibilidade de invocação a Deus no preâmbulo da Constituição não parecia ser algo que enfrentasse grandes resistências entre os legisladores. Pelo contrário:

já não se trata mais de se pedir a inclusão do nome de Deus no novo texto constitucional. Ao contrário, trata-se de algo mais simples: a manutenção do texto proposta pelo eminente Sr. Constituinte Bernardo Cabral, Relator da Comissão de Sistematização a quem aplaudimos juntamente com os Srs. Relatores Adjuntos, por terem destacado o valor da transcendência no preâmbulo da nossa futura Carta Magna (DANC, 27/01/1988, supl. B, p. 498-499).

O texto apresentado pelo Relator-Geral, portanto, vai à discussão apresentando o registro da invocação a Deus em seu preâmbulo. É de constituintes de esquerda, ligados ao PC do B e ao PT, que virão as críticas mais abertas. Reunidos para votação do projeto de Constituição apresentado por Bernardo $\mathrm{Cabral}^{27}$, no dia 24 de setembro de 1987, o deputado Haroldo Lima manifesta sua posição contrária à questão, reforçando que, apesar de reconhecer ser bastante aceita entre os constituintes a presença da expressão "sob a proteção de Deus" no texto do preâmbulo, e por mais que a maioria da população brasileira confessasse a fé cristã, a invocação representaria um desrespeito à minoria que não compartilha a mesma crença: "em se fazendo a Constituição ampla no Brasil, não cabe, agora, estarmos acentuando um aspecto que não é defendido por todo o povo brasileiro mas sim por uma facção do mesmo". Um preâmbulo que fosse abrangente a toda a população do país, portanto, não deveria comportar tal expressão (DANC, 27/01/1988, supl. C, p. 861-862). Coube, no entanto, a José Genoíno, constituinte eleito pelo PT paulista, a apresentação do Destaque $n^{\circ} 523 / 87$, que exigia a supressão da expressão "sob a proteção de Deus" do preâmbulo do projeto de Constituição.

O deputado petista inicia seu argumento tentando dirimir possíveis impressões de intolerância à religiosidade: alega que seu destaque significa, antes de qualquer coisa, um respeito profundo aos que estabelecem uma relação de intimidade "entre a divindade e a materialidade" - intimidade tão respeitável que, justamente por isto, não deveria ser estabelecida como critério a ser colocado no preâmbulo de uma Constituição. Após prosseguir com considerações a respeito da liberdade de crença e da separação formal entre a religião e o Estado, Genoíno volta à questão do respeito às crenças, enunciando sua preocupação com o risco de que a permanência da expressão

27 A $32^{\text {a }}$ Reunião Extraordinária, segundo registro dos Diários da Assembleia Nacional Constituinte, se iniciou em 24 de setembro de 1987 e encerrou-se 18 de novembro do mesmo ano. 
"sob a proteção de Deus" no preâmbulo do texto constitucional contribua, na verdade, para a vulgarização da crença religiosa: "colocar [a invocação a Deus] no texto constitucional significa banalizar algo que é muito profundo, para as pessoas que tem uma relação - como já falei - entre a divindade e a materialidade". O deputado conclui sua fala ressaltando que a Constituição, caso permaneça com o trecho que contesta, estará na verdade ferindo o pluralismo, a liberdade de crença e de religião. Segue-se daí uma indagação:

há muitas posições que diferem da religião católica, como ficariam com o argumento de dizer aqui que a maioria vai colocar no dia em que a religião católica fosse maioria e impusesse às outras religiões uma determinada formulação? (DANC, 27/01/1988, supl. C, p. 870-871).

Soa curiosa esta última citação - afinal, apesar de confusa, a fala do deputado pelo PT coloca em evidência a imagem católica que a discussão sobre a invocação a Deus no preâmbulo da Constituição repercute. Se está lidando, portanto, com a manutenção de um resquício político e cultural cuja matriz é católica - e não cristã, em um sentido mais amplo, ou até mesmo teísta. A história das reivindicações pelo registro da proteção divina nas Constituições brasileiras, como temos visto, é marcada por iniciativas de atores políticos católicos, iniciativas estas também contraditadas por políticos de diferentes orientações ideológicas e religiosas - inclusive protestantes.

Naquele dia, no entanto, a reação às alegações de José Genoíno não se fariam ressoar pelo pronunciamento de deputados católicos, mas pela manifestação dos deputados evangélicos Daso Coimbra (PMDB-RJ) e Enoc Vieira (PFL-MA).

A reação de Daso Coimbra ao discurso de José Genoíno transparece uma posição de combate. Suas primeiras palavras são também bíblicas - "Do Senhor é a Terra e sua plenitude, o mundo e os que nele habitam"28 - o que significa dizer, nas palavras do próprio deputado, que "habitamos a terra, e o mundo, e nesta condição, somos de Deus". Não caberia, portanto, recusa desta pertença e de sua proteção no preâmbulo, a não ser que se estivesse a negar a fé testemunhada e invocada pelo povo brasileiro. Para Coimbra, a dispensa desta invocação em respeito a "incrédulos, ateus, céticos ou infiéis" significaria o mesmo que igualar o povo e a fé pela exceção - e não poderia a Lei Maior do país "privilegiar a exceção". Querer "dispensar" - as aspas são reproduzidas no discurso de Coimbra - a proteção divina seria o mesmo que romper a tradição constitucional do país e desabrigar o povo de uma

28 O discurso não referencia a frase, mas ela se encontra no Livro dos Salmos, Capítulo 24, v. 1. 
proteção "que somente é dada, em especial, aos que a buscam". O deputado carioca profere suas últimas palavras como que em uma denúncia profética:

Deus, em sua Excelsa paciência, tem tolerado a ignorância dos incrédulos, mas não tolera o desprezo daqueles que $\mathrm{O}$ conhecendo, $\mathrm{O}$ negam e $\mathrm{O}$ recusam.

Nós, povo brasileiro, $\mathrm{O}$ conhecemos e não $\mathrm{O}$ recusamos. Por isto, não dispensamos sua proteção, sempre invocada na tradição constitucional e legislativa do País. E o povo não nos tolerará se minimizarmos a fé que busca em Deus sua permanente proteção. Sustento, portanto, a importância de constar no preâmbulo da Constituição a expressão “sob a proteção de Deus" (DANC, 27/01/1988, supl. C, p. 871).

Dizendo-se contemplado pela fala do deputado carioca, Enoc Vieira discursa em um tom aparentemente mais cordial. Faz referência ao Decálogo bíblico, a entendendo como a "Lei que rege a vida de todos os povos", e argumenta que, a partir do momento que o homem acredita em um Deus que é Criador de todas as coisas, em um Cristo que afirma que "sem mim nada podeis fazer", seria impossível se elaborar uma constituição que não tivesse a proteção de Deus. Se a separação entre Igreja e Estado era algo inegável, tampouco isto seria contrário à admissão de que todo o trabalho feito em benefício do povo deveria estar sempre sob o cuidado divino. Concluindo, o constituinte maranhense relembra novamente as palavras do salmista ao destacar que o substitutivo proposto por José Genoíno não poderia encontrar amparo nos corações e mentes daqueles que aceitam a Deus como protetor, criador e sustentador dos homens: “Bem-aventurada é a nação cujo Deus é o Senhor'. Busquemos sempre a proteção do nosso Deus, para sermos uma Nação bem-aventurada" (DANC, 27/01/1988, supl. C, p. 871-872).

A votação foi esmagadoramente contrária ao destaque de José Genoíno: dos 75 votos, 74 foram pelo "não" - incluindo os deputados Daso Coimbra e Enoc Vieira, além de outros evangélicos como Eraldo Tinoco, Manoel Moreira e Lysâneas Maciel, e parlamentares como Fernando Henrique Cardoso, José Serra, Miro Teixeira, Luiz Inácio Lula da Silva, Plínio de Arruda Sampaio e Roberto Freire. Este último, que havia sido eleito pelo PCB, ainda pediu para declarar seu voto "como marxista, ateu", esclarecendo que seu partido, em outras oportunidades, havia votado pela exclusão de qualquer referência a Deus na legislação, mas que seu partido, "na perspectiva de modernidade que existe no mundo socialista, não quer desrespeitar um sentimento deísta e religioso do povo brasileiro", assim justificando seu voto contra a retirada da invocação a Deus no preâmbulo (DANC, 27/01/1988, supl. C, p. 872).

O único voto favorável ao destaque foi o de Haroldo Lima, que vol- 
taria ao tema em 27 de janeiro de 1988. Naquele mês se iniciara o primeiro turno das discussões do projeto de Constituição apresentado pela Comissão de Sistematização, no Plenário da ANC. Apesar de o deputado comunista reconhecer que seu partido, o PC do B, não tinha disponibilidade de emendas para apresentar ao plenário, fez questão, no entanto, de reafirmar a posição do partido a respeito deste ponto do preâmbulo, recordando novamente os debates constitucionais sobre o tema ao longo do século XX, resgatando comparações com outros países igualmente religiosos que não adotaram a invocação a Deus em suas Cartas Magnas, e registando histórias conhecidas da própria Bíblia para reforçar suas posições - como o episódio em que Jesus, indagado sobre a efígie de César em uma moeda, responde a seus arguidores: "então, dê a Cézar o que é de Cézar" 29 - Lima remete-se a uma história de usos que considera oportunistas, desrespeitosas e farisaicas do nome de Deus, com objetivos políticos, tomando como exemplos o fascismo espanhol, e o uso da expressão "Deus seja louvado" nas moedas de cruzado que circulavam no Brasil à época. Com tudo isto, o deputado concluía que, "para que a separação entre o Estado e a Igreja prevalecesse, para que ninguém fosse obrigado a assinar texto contrário a suas convicções, para que não se evocassem poderes divinos para documentos políticos, relativos e temporários que serve mais a uns que a outros" e, finalmente, para que não se parecesse que "se estava utilizando Deus como cabo eleitoral", é que seu partido defendia a supressão da expressão "sob a proteção de Deus" do preâmbulo da Constituição (DANC, 28/01/1988, p. 6633).

Naquela sessão, os únicos a se manifestarem no mesmo sentido foram o deputado José Genoíno e o senador Mário Covas. Outros deputados elogiaram a presença da expressão - casos de José Maria Eymael (PDC-SP) e Brandão Monteiro (PDT-RJ). O evangélico Roberto Augusto (PTB-RJ) defendeu que a invocação a Deus representava que a Constituição estava a ser elaborada em um sentido que ia ao encontro dos anseios da Nação, "totalmente cristã". Mas Haroldo Lima foi alvo de uma reação categórica de outro constituinte evangélico: o paulista Fausto Rocha, batista e filiado ao PFL.

Segundo Rocha - que dizia defender para o preâmbulo expressão ainda mais explícita do que a presente no projeto em discussão ("pedindo

29 Reproduzimos o trecho disponível no DANC, 28/01/1988, p. 6633. Na passagem bíblica em questão, Jesus é indagado por autoridades religiosas se era lícito pagar tributo a César, Imperador de Roma. A depender da resposta, sim ou não, Cristo poderia colocar o povo contra si ou ter de responder à autoridade romana por negar-lhe o imposto. Jesus pede, então, que lhe mostrem um denário - uma moeda da época - que tinha a efígie do imperador. Ao questionar os homens da lei sobre de quem era tal efígie, e ouvir a resposta de que era de César, Cristo retruca: "Dai, pois, a César o que é de César e a Deus o que é de Deus” (Mt. 22:15-22; ver também Mc. 12:13-17 e Lc. 20: 20-26). 
a inspiração de Deus") - leis justas e o desejo de cumpri-las eram algo importante, mas não mais do que a necessidade de uma renovação moral e comportamental, com embasamento espiritual, que trazia "a necessidade fundamental de Deus antes e acima de qualquer lei”. A invocação a Deus não era simplesmente algo que fazia jus à fé e à cultura do povo brasileiro, mas a representação das promessas de Deus que desejava ver cumpridas na história - pois “é preciso conhecer e viver os princípios da palavra de Deus para ser abençoado". Permanece, assim, o constante diálogo entre o político e terreno e o espiritual. Cristo é a referência, tão importante e digna de reconhecimento até por seu sacrifício por aqueles que o negam. Afinal, "Cristo morreu também pelos comunistas, ateus, agnósticos. Deu sua vida para que essas pessoas possam reformular o seu pensamento e, em aceitando a Jesus Cristo como seu único e suficiente salvador, regenerar sua vida, ter amor pelo próximo e defender todas as liberdades" (DANC, 28/01/1988, p. 6634).

Naquele dia, em que se discutia emenda substitutiva apresentada pelo deputado Aluízio Campos (PMDB-PB) para o preâmbulo da Constituição, a votação seria adiada por falta de quórum. No dia seguinte, com 487 votos, a emenda foi aprovada (cf. DANC, 28/01/1988, p. 6639-6641; 29/01/1988, p. 6672-6674).

\section{Conclusões e Observações}

O objetivo deste artigo foi apresentar a importância do debate protagonizado pelos deputados evangélicos a respeito da presença de um exemplar da Bíblia Sagrada na Mesa da Assembleia Nacional Constituinte, e da defesa da inscrição "sob a proteção de Deus" no preâmbulo da Constituição ao qual o parlamento dedicava seus esforços. Em princípio, apresentamos as iniciativas de parlamentares da "bancada evangélica" para que a Bíblia passasse a constar regimentalmente no interior do recinto da $\mathrm{ANC}$, e como esta demanda foi defendida com diferentes significados: se, por um lado, houve momentos em que a retórica foi orientada para a apresentação de um caráter universalista e histórico do livro sagrado dos cristãos, que justificaria a importância da presença deste objeto entre os constituintes para que o tivessem como uma referência para seus trabalhos, independentemente de suas crenças; por outro lado, muitos foram os pronunciamentos que buscaram reforçar a presença do discurso e da fé cristã - não se valendo da Bíblia simplesmente como uma "metáfora", um "registro histórico", mas como um recurso de legitimação dos sentidos a serem assumidos pela Lei Maior e pelo Estado brasileiro, cuja organização se disputava na feitura da nova Constituição: seria feliz a Na- 
ção que tivesse por base a Palavra de Deus, e cujos homens pautassem suas condutas pelas palavras divinas; deveria ser a Bíblia a fonte dos princípios a transparecerem na nova Carta Magna.

Em seguida, notamos que, diferente de outros contextos constituintes, em que as iniciativas para a garantia de inscrições que fizessem referência a Deus no preâmbulo da Constituição eram sobretudo católicas, os parlamentares da Constituinte de 1987-1988 não se depararam com atitudes semelhantes, mas com a tentativa de exclusão deste registro - uma vez que, desde a primeira versão apresentada pela Comissão de Sistematização, a invocação a Deus esteve presente no preâmbulo. Desejamos, neste sentido, evidenciar as reações dos deputados evangélicos aos comentários críticos a esta invocação, algumas delas bastante acaloradas, mostrando a sustentação de um discurso que procurava dar uma marca cristã aos novos marcos legais do país. Se era baixa a resistência à invocação a Deus no preâmbulo - como vimos, mesmo entre deputados não religiosos, ou do campo da esquerda, não houve grandes articulações no sentido de reagirem a esta proposição - os evangélicos, por outro lado não deixaram de ser categóricos na defesa desta posição.

Cabem algumas considerações. Primeiro, que é importante ressaltar a recordação constante de um cristianismo majoritário no conjunto da população brasileira, e de uma fé cristã apresentada como um eixo da formação histórica do país, como justificativas para estas demandas entre os parlamentares evangélicos. Fausto Rocha, defendendo a inscrição "sob a proteção de Deus" no preâmbulo, afirmou que, se nem toda a nação brasileira era constituída de cristãos, no entanto o Brasil era a maior nação cristã do mundo - com evangélicos, católicos e outras diversas denominações - e que para esta maioria seria uma honra, um orgulho e um privilégio, ver tal aspiração cumprida; Daso Coimbra denunciou a recusa a esta invocação como uma negação da fé do povo brasileiro e da tradição constituição erigida no país; para Antônio de Jesus, a presença da Bíblia nas atividades da Constituinte era uma maneira de conectar os parlamentares com as crenças deste povo fundamentalmente cristão que era o povo brasileiro; nossa pátria nascera sob o signo da cruz, diria Costa Ferreira. No conjunto de seus discursos, os evangélicos buscam representar esta ampla face cristã da formação do Brasil e de seu povo, reivindicando a presença da Bíblia e a invocação a Deus como expressões desta identidade.

Mas, especialmente no caso da colocação da Bíblia na Mesa da Constituinte, os evangélicos enfatizam isto como uma sinalização da fé cristã dos brasileiros, mas também como uma demanda dos evangélicos - e a afirmação desta, por meio da menção constante ao objeto presente nas sessões, ou 
até mesmo pela vigilância por sua presença, reforça a presença simbólica da representação parlamentar evangélica em conexão com um contexto mais amplo de disputas: o do campo religioso. De certo modo, não seria absurdo afirmar que os evangélicos tiveram algum sucesso nesta iniciativa. Simplesmente não identificamos registros de menções dos deputados à presença do crucifixo, uma histórica marca católica dentro do parlamento, como uma forma de legitimar discursos e posições políticas. Por outro lado, atores católicos envolvidos nos debates constituintes fizeram menção à presença da Bíblia ali posta por iniciativa dos evangélicos. Destaco, neste caso, a fala de Dom Raymundo Damasceno de Assis, que pronunciou: "sabemos que a presença de Deus se faz notar, quotidianamente, nesta Casa através de Sua Palavra, consignada na Bíblia Sagrada, exposta por força regimental sobre a Mesa da Assembleia Nacional Constituinte" (DANC, 27/01/1988, p. 499).

O deputado Salatiel Carvalho, como vimos, considerou a inclusão da Bíblia na Mesa da ANC como a primeira grande vitória do bloco parlamentar evangélico. Outros debates e disputas se fariam presentes. A afirmação de seus símbolos no espaço parlamentar e a defesa da inspiração divina para os trabalhos constituintes foram alguns dos caminhos que permitiram aos evangélicos demarcar sua presença na ANC.

\section{Referências bibliográficas}

BRASIL. Constituição da República Federativa do Brasil: texto constitucional promulgado em 5 de outubro de 1988, com as alterações adotadas pelas emendas constitucionais $n^{\circ} 1 / 1992$ a 99/2017, pelo Decreto legislativo $n^{\circ}$ 186/2008 e pelas emendas constitucionais de revisão $n^{\circ} 1$ a 6/1994. 53. ed. Brasília: Câmara dos Deputados, Edições Câmara, 2018.

BRASIL, Assembleia Nacional Constituinte. Projeto de Resolução n²-A, de 1987. Brasília: Centro Gráfico do Senado Federal. Disponível em: <http://www.camara.gov.br/internet/ constituicao20anos/DocumentosAvulsos/vol-327.pdf>, 1987.

Diários da Assembleia Nacional Constituinte. Brasília: Centro Gráfico do Senado Federal, 1987-1988.

DALLARI, D. DE A. Preâmbulos das Constituições do Brasil. Revista da Faculdade de Direito, Universidade de São Paulo, v. 96, n. 0, p. 243-270, 1 jan. 2001.

FRESTON, P. Protestantes e Política no Brasil: da Constituinte ao Impeachment. 1993. Tese de Doutorado - UNICAMP, Campinas, 1993.

GIUMBELLI, E. Crucifixos em recintos estatais e monumento do Cristo Redentor: distintas relações entre símbolos religiosos e espaços públicos. In: ORO, ARI PEDRO et al. (Org.). A religião no espaço público: atores e objetos. São Paulo: Terceiro Nome, 2012. p. 45-60. HUXLEY, T. H. Critiques and addresses. London, Macmillan, 1883.

PIERUCCI, A. F. Representantes de Deus em Brasília: a bancada evangélica na Constituinte. A realidade social das religiões no Brasil: religião, sociedade e politica. São Paulo: Hucitec, 1996, p. 163-191. 
PILATTI, A. A Constituinte de 1987-1988: progressistas, conservadores, ordem econômica e regras do jogo. Rio de Janeiro: PUC-Rio; Lumen Juris, 2008.

PINHEIRO, D. A. R. Direito, estado e religião: a constituinte de 1987/1988 e a (re)construção da identidade religiosa do sujeito constitucional brasileiro. 2008. Dissertação de Mestrado Universidade de Brasília, Brasília, 2008.

RANQUETAT JÚNIOR, C. A. A presença da Bíblia e do crucifixo em espaços públicos no Brasil: religião, cultura e nação. In: ORO, ARI PEDRO et al. (Org.). A religião no espaço público: atores e objetos. São Paulo: Terceiro Nome, 2012a. p. 61-79.

Laicidade à brasileira: um estudo sobre a controvérsia em torno da presença de símbolos religiosos em espaços públicos. 2012b. Tese de Doutorado - UFRGS, 2012.

ROCHA, A. S. Genealogia da constituinte: do autoritarismo à democratização. Lua Nova: Revista de Cultura e Política, n. 88, p. 29-87, 2013.

RODRIGUES, L. M. Quem é quem na Constituinte: uma análise sócio-política dos partidos e deputados. São Paulo: Oesp-Maltese, 1987.

Submetido em: 13-8-2018

Aceito em:19-12-2018 